\title{
Queen's to redress harms of historic ban on black medical students
}

\author{
n Cite as: CMAJ 2019 July 2;191:E746. doi: 10.1503/cmaj.109-5769
}

Posted on cmajnews.com on June 11, 2019.

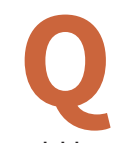

ueen's University has established a fund for black medical students after formally revoking a centuryold ban on their admission.

The university introduced the ban on black medical students in 1918 and enforced it until 1965. But the policy remained on the books until last fall, when cultural studies doctoral candidate Edward Thomas called for a formal repeal. Queen's officially revoked the ban in October and issued a formal apology in April. The faculty of health sciences also struck a commission on black medical students to redress harms of the ban.

According to Dr. Richard Reznick, dean of the faculty of health sciences, "This policy was so undeniably unjust, and I knew that formally rescinding the motion had to be only the beginning of the process of making amends for this wrong."

The new commission recently established a Medicine Admission Award for Black Canadians. Financial support up to $\$ 50000$ will be available to students admitted in 2019 who demonstrate financial need and academic achievement.

The commission also sent letters of apology to families whose relatives were affected by the ban. Queen's pushed out 15 black students when the policy was introduced in 1918, ending the medical careers of at least two upper-year students in good standing. Eight students who resisted the ban and continued their studies faced racist threats and mockery. The medical school said it would arrange for transfers to other schools, but there's no evidence that it did.

At the time, the university justified the ban claiming that veterans of the First World War were refusing treatment by black students, making their continued

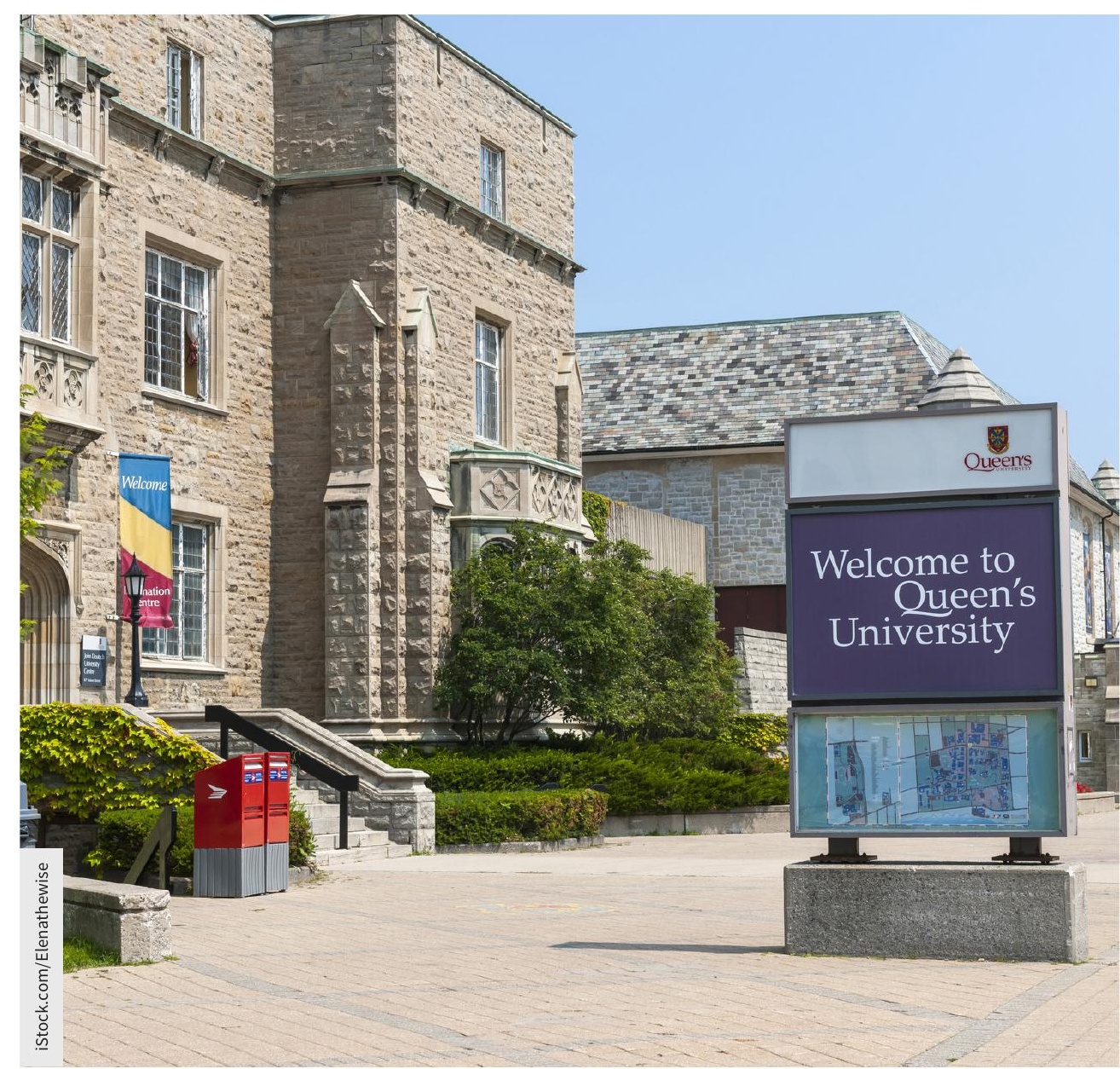

A new fund will provide financial support for black medical students as part of reconciliation for racist policies.

training impossible. However, archival research suggests the medical school banned black students to get a higher ranking from the American Medical Association, which favoured racial segregation policies, and thus more funding from American foundations.

According to Reznick, "This lack of transparency continued in later years, as university leadership misrepresented the ban or failed to hold Queen's accountable for its actions."

Queen's will introduce curricular content this fall to educate medical students about the historic and ongoing effects of the ban. The commission will also establish a permanent exhibit about the ban in the medical school's atrium.

Lauren Vogel, CMAJ 